Research Paper

\title{
Non-response to preoperative chemotherapy is a contraindication to hepatectomy plus radiofrequency ablation in patients with colorectal liver metastases
}

\author{
Rui Mao ${ }^{1, *}$, Jian-Jun Zhao ${ }^{1, *}$, Hong Zhao ${ }^{1}$, Ye-Fan Zhang ${ }^{1}$, Xin-Yu Bi ${ }^{1}$, Zhi-Yu Li ${ }^{1}$, \\ Jian-Guo Zhou ${ }^{1}$, Xiao-Long $\mathbf{W u}^{1}$, Chen $\mathrm{Xiao}^{1}$ and Jian-Qiang Cai ${ }^{1}$ \\ ${ }^{1}$ Department of Hepatobiliary Surgery, Cancer Hospital, CAMS, Beijing 100021, P.R.China \\ *These authors have contributed equally to this work \\ Correspondence to: Jian-Qiang Cai, email: caijianqiang188@sina.com
}

Hong Zhao, email: pumczhaohong@126.com

Keywords: colorectal liver metastases, hepatectomy, radiofrequency ablation, preoperative chemotherapy, response Received: July 03, $2017 \quad$ Accepted: August 08, $2017 \quad$ Published: September 05, 2017

Copyright: Mao et al. This is an open-access article distributed under the terms of the Creative Commons Attribution License 3.0 (CC BY 3.0), which permits unrestricted use, distribution, and reproduction in any medium, provided the original author and source are credited.

\section{ABSTRACT}

The long-term outcome of $\mathbf{2 2 8}$ patients with colorectal liver metastases (CRLM) who underwent preoperative chemotherapy followed by hepatectomy \pm RFA were retrospectively analyzed. Stratified by chemotherapy response, patients were divided into responding $(n=129)$ and non-responding groups $(n=99)$. Patients who underwent hepatectomy-RFA had a greater number of metastases (median of 4 vs. $2, p=0.000$ ), a higher incidence of bilobar involvement ( $66.7 \%$ vs. $49.1 \%, p=0.014)$ and longer chemotherapy cycles (median of 6 vs. $4, p=0.000$ ). In the responding group, the median overall survival (OS) and recurrence free survival (RFS) of hepatectomyRFA and the hepatectomy alone subgroups were comparable (38.6 months vs. 43.2 months, $p=0.824 ; 8.2$ months vs. 11.4 months, $p=0.623$ ). In the non-responding group, the median OS and RFS of patients treated with hepatectomy-RFA were significantly shorter (18.5 months vs. 34.2 months, $p=0.000 ; 5.1$ months vs. 5.9 months, $\mathrm{p}=\mathbf{0 . 0 0 2}$ ). RFA was identified as the unfavorable independent factor for both OS (HR=3.60, 95\%CI =1.81-7.16, $\mathrm{p}=0.039)$ and $\mathrm{RFS}(\mathrm{HR}=1.70,95 \% \mathrm{CI}=1.00-2.86$, $p=0.048$ ) in non-responsive patients. Local recurrence rate after hepatectomy-RFA was higher in the non-responding group ( $48.1 \%$ vs. $23.6 \%, p=0.018)$. Non-response to preoperative chemotherapy may be a contraindication to hepatectomy-RFA in patients with CRLM.

\section{INTRODUCTION}

Liver is the most frequent site for metastasis from colorectal cancer, with more than $50 \%$ of patients developing hepatic metastases during the course of the disease $[1,2]$. Liver resection combined with modern chemotherapy is considered the treatment of choice for patients with CRLM [3,4]. For CRLM judged to be resectable, preoperative chemotherapy is considered a standard of care in most Western countries [5]. For patients with CRLM not eligible for resection at diagnosis due to risk of subsequent liver insufficiency or maldistribution of hepatic metastases, chemotherapy can convert the unresectable or borderline resectable cases into resectable disease [6-10]. Besides, a correlation between response to preoperative chemotherapy and long-term outcome has also been confirmed [11].

RFA, as a complement of hepatic resection, allows surgeons to ablate small lesions while resecting large ones, aiming to preserve adequate liver parenchyma. However, the therapeutic efficacy of hepatectomyRFA in the treatment of CRLM remains controversial because of relatively high intrahepatic recurrence rate and unfavorable survival [12-14]. It should be noted that 
patients treated with resection-RFA or resection alone were different for baseline tumor characteristics [15]. It is hard to determine whether RFA impacts survival negatively because of a more aggressive disease biology that makes treatment with resection alone impossible. Therefore, it is more reasonable to identify a group of patients who will benefit from this treatment modality.

Previous studies have demonstrated that good longterm outcomes can be achieved by a combination of prior chemotherapy and RFA with or without liver resection in patients with unresectable CRLM [16-18]. We postulate chemotherapy response could also predict therapeutic effect of this treatment. However, the proportions of patients receiving preoperative chemotherapy vary among studies, and the impact of response on outcome is seldom assessed. In current study, we compared the outcome of patients treated with hepatic resection alone or resection-RFA, grouped by response to preoperative chemotherapy. The clinical efficacy of hepatectomy-RFA was comparable to hepatectomy alone in patients who responded to preoperative chemothearpy. Whereas, the long-term results of non-responding patients who underwent hepatectomy-RFA were significantly worse.

\section{RESULTS}

\section{Patient characteristics}

The clinicopathologic features of the patients in the study are displayed in Table 1 . The study population comprised 228 patients (145 men and 83 women; median age, 54 years). Most patients (83.8\%) developed synchronous liver metastases. $75.9 \%$ of the patients had more than one metastases, with a median of 3 lesions, and a maximum of 9 lesions. The median diameter of the largest lesion was $2.8 \mathrm{~cm}$, and $49.6 \%$ of patients had lesions larger than $3 \mathrm{~cm}$. Bilobar distribution of metastases was observed in $54.4 \%$ of the patients. Preoperative chemotherapy regimens included oxaliplatin-based (70.2\%), irinotecan-based (17.1\%), oxaliplatin and irinotecan-based (12.7\%). Biological agents were included in preoperative regimens for $28.5 \%$ of the patients. The median number of preoperative chemotherapy cycles was 5, with 46 patients $(20.2 \%)$ receiving at least 8 cycles. PR, SD and PD to preoperative chemotherapy were observed in 129 (56.3\%), 68 (29.8\%) and 31 (13.6\%) patients respectively. A total of 69 patients $(30.3 \%)$ underwent hepatectomy in combination with RFA; 159 patients $(69.7 \%)$ underwent hepatectomy alone. The total number of resected lesions were 570, averaging 2.5 per patient, with 148 lesions treated by RFA (2.1 per patients). The median diameter of resected and abalted lesions were $2.6 \mathrm{~cm}$ and $2.1 \mathrm{~cm}$, respectively. 81 patients $(35.5 \%)$ had margin invasion, and major complications were reported in 39 patients (17.1\%). Postoperative chemotherapy for CRLM was administered to 196 patients $(86.0 \%)$.

Patients who underwent hepatectomy-RFA had a greater number of total liver lesions (median of 4 vs. 2, $\mathrm{p}=0.000$ ). Bilobar distribution of liver lesions was also more common in patients who underwent hepatectomyRFA $(66.7 \%$ vs. $49.1 \%, p=0.014)$. The median cycle of preoperative in hepatectomy-RFA cohort was six, compared with the four cycles in hepatectomy alone group $(p=0.000)$. The proportion of patients who developed major complications were $29.0 \%$ and $11.9 \%$ after hepatectomyRFA or hepatectomy alone, respectively $(\mathrm{p}=0.002)$.

\section{Overall survival}

The median follow-up of the entire study population was 32 months. A total of 98 patients $(42.9 \%)$ died during follow-up. Median survival was 35.7 months. The 1-, 3 -, and 5-year OS rates were $93.3 \%, 50.5 \%$, and $20.8 \%$, respectively. According to response to preoperative chemotherapy, the included patients were divided into responding group $(\mathrm{PR}, \mathrm{n}=129)$ and non-responding group ( $\mathrm{SD} / \mathrm{PD}, \mathrm{n}=99)$. Risk factors for decreased OS are displayed in Table 2.

For all included patients, there was no significant difference in survival rate between the patients who underwent hepatectomy-RFA and those treated by hepatectomy alone at 5 years $(22.3 \%$ vs. $20.9 \%$, $\mathrm{p}=0.096$ ) (Figure 1A). Preoperative chemotherapy cycles $(p=0.001)$, regimens $(p=0.006)$, and responses $(p=0.005)$; primary tumor lymph node metastases $(\mathrm{p}=0.01)$; liver lesion numbers $(p=0.001)$, distribution $(p=0.001)$, and diameters $(p=0.057)$; resection margin status $(p=0.015)$, and major complications $(p=0.000)$ were associated with OS in univariate analysis. In multivariate analysis, $\geq 4$ hepatic metastases $(\mathrm{p}=0.008)$, bilobar distribution $(\mathrm{p}=0.000)$, non-responsive to chemotherapy $(\mathrm{p}=0.003)$, lymph node metastases $(\mathrm{p}=0.44)$ and major complications $(\mathrm{p}=0.000)$ predicted decreased OS for the whole cohort of patients.

The median follow-up of the responding group (129 patients) was 31.6 months. 5-year survival rate of hepatectomy-RFA and the hepatectomy alone subgroups were comparable $(30.7 \%$ vs. $33.6 \%, p=0.824)$ (Figure 1B). Multivariate analysis revealed that prolonged chemotherapy $(\mathrm{p}=0.01)$, and major complications $(p=0.002)$ remained as significant predictive factors for unfavorable survival.

The median follow-up of the non-responding group (99 patients) was 32 months. The median survival time for 27 patients who received hepatectomy-RFA was 18.5 months, significantly shorter than 34.2 months observed in those treated with hepatectomy alone $(\mathrm{p}=0.000)$ (Figure $1 \mathrm{C})$. In multivariate analysis, intraoperative RFA $(\mathrm{p}=0.039)$ and bilobar distribution $(p=0.001)$ were the predictors of worse OS.

\section{Recurrence-free survival}

Risk factors for decreased RFS are displayed in Table 3. For the entire study population, the median 
Table 1: Clinicopathologic characteristics of patients with CRLM sorted by treatment

\begin{tabular}{|c|c|c|c|c|}
\hline & All Patients $n=228$ & Resection alone $n=159$ & Resection+RFA n=69 & $\mathbf{p}$ \\
\hline Male sex, n (\%) & $145(63.6)$ & $100(62.9)$ & $45(65.2)$ & 0.738 \\
\hline Age, (range) & $54(28-79)$ & $54(28-79)$ & $55(29-72)$ & 0.570 \\
\hline Age $\geq 60, \mathrm{n}(\%)$ & $71(31.1)$ & $50(38.8)$ & $21(30.4)$ & 0.88 \\
\hline Preoperative CEA, (range), ng/ml & $7.6(0.8-1503.0)$ & $7.0(0.8-1503.0)$ & $9.3(1.3-147.0)$ & 0.527 \\
\hline Preoperative CEA $\geq 10 \mathrm{ng} / \mathrm{ml}, \mathrm{n}(\%)$ & $97(42.5)$ & $65(40.9)$ & $32(46.3)$ & 0.441 \\
\hline \multicolumn{5}{|l|}{ Primary site, $\mathrm{n}(\%)$} \\
\hline Colon & $137(60.1)$ & $86(54.1)$ & $41(59.4)$ & 0.456 \\
\hline Left hemicolon & $195(85.5)$ & $138(86.8)$ & $57(82.6)$ & 0.409 \\
\hline Synchronous metastasis, $\mathrm{n}(\%)$ & $191(83.8)$ & $131(82.4)$ & $60(87.0)$ & 0.390 \\
\hline T3-4, n (\%) & 207(90.8) & $146(91.8)$ & $61(88.4)$ & 0.412 \\
\hline Positive lymph nodes, $\mathrm{n}(\%)$ & $154(67.5)$ & $108(67.9)$ & $46(66.7)$ & 0.852 \\
\hline Lymphovascular invasion & $79(34.6)$ & $56(35.2)$ & $23(33.3)$ & 0.783 \\
\hline Perineural invasion & $80(35.1)$ & $60(37.7)$ & $20(29.0)$ & 0.203 \\
\hline KRAS mutation, $\mathrm{n}(\%) *$ & $56(40.6)$ & $33(39.8)$ & $23(41.8)$ & 0.809 \\
\hline$\geq 4$ hepatic metastases, $\mathrm{n}(\%)$ & $99(43.4)$ & $51(32.1)$ & $48(69.6)$ & 0.000 \\
\hline Number of metastases, (range) & $3(1-9)$ & $2(1-8)$ & $4(2-9)$ & 0.000 \\
\hline Number of ablated lesions, (range) & - & - & $2(1-4)$ & - \\
\hline Number of resected lesions, (range) & $2(1-8)$ & $2(1-8)$ & $2(1-5)$ & 0.053 \\
\hline Bilobar distribution, $\mathrm{n}(\%)$ & $124(54.4)$ & $78(49.1)$ & $46(66.7)$ & 0.014 \\
\hline Biggest metastatic volume in cms, (range) & $2.8(0.5-10)$ & $2.8(0.5-10)$ & $3(0.5-8.5)$ & 0.338 \\
\hline Largest diameter $\geq 3 \mathrm{~cm}, \mathrm{n}(\%)$ & $113(49.6)$ & $76(47.8)$ & $37(53.6)$ & 0.419 \\
\hline \multicolumn{5}{|l|}{ Preoperative chemotherapy regimen, n (\%) } \\
\hline oxaliplatin & $160(70.2)$ & $107(67.3)$ & $53(76.8)$ & 0.149 \\
\hline irinotecan & $39(17.1)$ & $24(15.1)$ & $15(21.7)$ & 0.221 \\
\hline Oxaliplatin+irinotecan & $29(12.7)$ & $22(13.8)$ & $7(10.1)$ & 0.442 \\
\hline Biological agents, $\mathrm{n}(\%)$ & $65(28.5)$ & $42(26.4)$ & $23(33.3)$ & 0.288 \\
\hline Preoperative chemotherapy cycles, (range) & $5(2-22)$ & $4(2-14)$ & $6(2-22)$ & 0.000 \\
\hline Preoperative chemotherapy cycles $\geq 8, \mathrm{n}(\%)$ & $46(20.2)$ & $22(13.8)$ & $24(34.8)$ & 0.000 \\
\hline Response to chemotherapy, n (\%) & $129(56.3)$ & $87(54.7)$ & $42(60.9)$ & 0.389 \\
\hline \multicolumn{5}{|l|}{ Surgical procedure } \\
\hline Nonanatomical resection & $171(75.0)$ & $115(72.3)$ & $56(81.1)$ & 0.157 \\
\hline Anatomical resection & $25(11.0)$ & $21(13.2)$ & $4(5.8)$ & 0.1 \\
\hline Anatomical+nonanatomical resection & $32(14.0)$ & $23(14.5)$ & $9(13.0)$ & 0.776 \\
\hline Positive surgical margins, $\mathrm{n}(\%)$ & $81(35.5)$ & $55(34.6)$ & $26(37.7)$ & 0.654 \\
\hline Postoperative chemotherapy, n (\%) & $196(86.0)$ & $135(84.8)$ & $61(88.4)$ & 0.485 \\
\hline Major complications, $\mathrm{n}(\%)$ & $39(17.1)$ & 19(11.9) & $20(29.0)$ & 0.002 \\
\hline
\end{tabular}

RFA=Radiofrequency Ablation. $C R L M=$ Colorectal Liver metastases. $C E A=$ Carcino-embryonic antigen. KRAS=Kirsten rat sarcoma viral oncogene.

* KRAS status was available in 138 patients. 
recurrence-free survival was 7.7 months. The 1-, 3-, and 5-year RFS rates were $33.7 \%, 19.4 \%$, and $13.6 \%$, respectively. Patients who underwent hepatectomy alone had a longer median RFS than patients who underwent hepatectomy-RFA (9.0 months vs. 6.2 months, $\mathrm{p}=0.05$ ) (Figure 2A). Preoperative chemotherapy cycles $(p=0.001)$, regimens $(p=0.006)$, and responses $(p=0.005)$; primary tumor lymph node metastases $(\mathrm{p}=0.011)$, and perinueral invasion $(p=0.008)$; liver lesion numbers $(\mathrm{p}=0.000)$, and distribution $(\mathrm{p}=0.001)$; surgical procedure $(p=0.024)$, resection margin status $(p=0.001)$, and major complications $(p=0.000)$ were associated with RFS in univariate analysis. In multivariate analysis, predictive factors for decreased RFS were $\geq 4$ hepatic metastases $(p=0.000)$, non-responsive to chemotherapy $(p=0.002)$, and major complications $(\mathrm{p}=0.015)$.

In the responding group (129 patients), the median RFS of patients who underwent hepatectomy-RFA was 8.2 months, not significantly different from the 11.4 months after treatment of hepatectomy alone $(\mathrm{P}=0.623)$ (Figure 2B). Multivariate analysis demonstrated that bilobar distribution $(\mathrm{p}=0.007)$, and prolonged chemotherapy $(\mathrm{p}=0.002)$ were independent predictors for recurrence.

In the non-responding group (99 patients), all patients who received hepatectomy-RFA experienced recurrence within one year of operation, while the 3-year RFS rate for patients after hepatectomy alone was $19.7 \%(p=0.002)$ (Figure 2C). In multivariate analysis, the significant predictors of higher recurrence was intraoperative RFA ( $p=0.048)$, and $\geq 4$ hepatic metastases $(p=0.000)$.

\section{Patients who underwent hepatectomy-RFA}

A separate analysis was performed in sixty-nine patients who underwent hepatectomy-RFA. The median survival of the responding group was 42.3 months, significantly longer than the 18.5 months in the nonresponding group $(\mathrm{p}=0.000)$ (Figure $3 \mathrm{~A})$. A significant difference was also found in RFS between the two groups (8.2 months vs. 5.1 months, $\mathrm{p}=0.000$ ) (Figure 3B). Multivariate analysis demonstrated that non-responsive to chemotherapy $(p=0.000)$ and $\geq 4$ hepatic metastases $(p=0.008)$ were independent predictors for unfavorable survival. The predictive factors for recurrence were non-responsive to chemotherapy $(\mathrm{p}=0.013)$, and major complications $(\mathrm{p}=0.000)$.

\section{Patterns of recurrence}

A total of $167(73.2 \%)$ patients experienced recurrence, including intrahepatic, extrahepatic, and both intra- and extrahepatic recurrences in 128 (56.1\%), 11 $(4.8 \%)$ and $28(12.3 \%)$ patients, respectively. Differences in recurrence patterns among the treatment groups is shown in Table 4. The overall recurrence rate after
hepatectomy-RFA and hepatectomy alone were $76.8 \%$ and $71.7 \%$, respectively $(\mathrm{p}=0.423)$. The dominant pattern of recurrence was intrahepatic (63.8\% vs. $52.8 \%$, $\mathrm{p}=0.126)$; local recurrence rate at the ablation site/resection margin was documented in $31.9 \%$ of patients who underwent hepatectomy-RFA, compared with $18.2 \%$ after hepatecomy alone $(\mathrm{p}=0.023)$. The proportion of patients in two treatment groups found to have extrahepatic or both intra- and extrahepatic recurrences was similar.

Recurrence pattern after surgery in the responding and non-responding groups is shown in Table 5. In the non-responding group, recurrence of any kind occurred more frequently after hepatectomy-RFA (92.6\%), versus that after resection alone $(76.4 \%, \mathrm{p}=0.068)$. Both intrahepatic and local recurrence rates after hepatectomyRFA were significantly higher than those in patients treated with resection alone $(77.8 \%$ vs. $55.6 \%, \mathrm{p}=0.043 ; 48.1 \%$ vs. $23.6 \%, p=0.018)$. Rate of recurrence at the ablation site was comparable to that at the margin after resection alone, whether in the entire group $(17.4 \%$ vs. $18.2 \%, \mathrm{p}=0.868)$ or both subgroups separately (responding group: $11.9 \%$ vs. $13.8 \%, \mathrm{p}=0.766$; non-responding group: $25.9 \%$ vs. $23.6 \%$, $\mathrm{p}=0.8111$ ). Significant differences in recurrence patterns between two treatment modalities were not observed in the responding group.

\section{DISCUSSION}

Improvements in preoperative chemotherapy and combination hepatectomy with RFA allow radical treatment for an increased number of patients with CRLM. This study suggested that the benefits associated with this treatment modality were strongly impacted by response to chemotherapy.

The median survival of the entire study population was 35.7 months in present study, inferior to the reported survival of 40.5-48.2 months after conversion therapy [19-21]. We attributed this to the relatively lower response rate $(56.3 \%$ ) compared to a mean value of $74 \%$ (range $60-100 \%$ ) reported in previous studies [20]; and the variable definition of resectability. The median RFS after conversion therapy was 7.7 months, which is in line with previous results (3.2-10.6 months) [19-21], reaffirming the finding of relatively short RFS and a prolonged OS after conversion therapy followed by surgery.

Objective evaluation of hepatectomy-RFA compared to resection alone is difficult. Indeed, patients who underwent hepatectomy-RFA were characterized by greater number and more widespread distribution of liver lesions in current study. Besides, these patients seem to be less sensitive to chemotherapy (prolonged chemotherapy was required in $34.8 \%$ of patients). Recently, Imai et al used propensity score matching to overcome imbalance of background characteristics [22]. After matching, overall and disease free survival in hepatectomy-RFA group were not different from those of patients treated with 
Table 2: Multivariate analysis of clinicopathologic factors associated with overall survival in patients with CRLM according to the response to preoperative chemotherapy

\begin{tabular}{|c|c|c|c|c|}
\hline & Median OS (months) & 5-year OS (\%) & HR $(95 \%$ CI) & multivariate $p$ \\
\hline \multicolumn{5}{|l|}{ All patients $(n=228)$} \\
\hline$\geq 4$ hepatic metastases & 29.7 & 11.3 & $1.54(1.00-2.35)$ & 0.008 \\
\hline Bilobar distribution & 31.4 & 9.4 & $2.32(1.51-3.59)$ & 0.000 \\
\hline $\begin{array}{l}\text { Non-responsive to } \\
\text { chemotherapy }\end{array}$ & 31.6 & 11.1 & $1.89(1.25-2.86)$ & 0.003 \\
\hline Positive lymph nodes & 33.8 & 16.0 & $1.66(1.01-2.71)$ & 0.44 \\
\hline Major complication & 24.1 & 12.4 & $2.52(1.56-4.06)$ & 0.000 \\
\hline \multicolumn{5}{|l|}{ Responding group $(\mathrm{n}=129)$} \\
\hline $\begin{array}{l}\text { Preoperative } \\
\text { chemotherapy cycles } \geq 8\end{array}$ & 33.8 & 0 & $3.26(1.61-6.61)$ & 0.01 \\
\hline Major complication & 24.1 & 13.2 & $3.37(1.56-7.32)$ & 0.002 \\
\hline \multicolumn{5}{|l|}{$\begin{array}{l}\text { Non-responding group } \\
(\mathrm{n}=99)\end{array}$} \\
\hline Intraoperative RFA & 18.5 & 0 & $3.60(1.81-7.16)$ & 0.039 \\
\hline Bilobar distribution & 20.7 & 0 & $2.13(1.20-3.79)$ & 0.01 \\
\hline
\end{tabular}

RFA=Radiofrequency Ablation. CRLM=Colorectal Liver Metastases. OS=Overall Survival.

$\mathrm{HR}=$ Hazard Ratio. $\mathrm{CI}=$ Confidence Interval.

Table 3: Multivariate analysis of clinicopathologic factors associated with recurrence free survival in patients with CLM according to the response to preoperative chemotherapy

\begin{tabular}{lcccc}
\hline & Median RFS (months) & 3-year RFS (\%) & HR (95\% CI) & multivariate p \\
\hline All patients ( $\mathrm{n}=228)$ & & & & \\
$\quad$ \4 hepatic metastases & 5.6 & 11.3 & $1.87(1.35-2.58)$ & 0.000 \\
$\quad$ Non-responsive to chemotherapy & 5.1 & 14.9 & $1.67(1.21-2.29)$ & 0.002 \\
$\quad$ Major complication & 4.9 & 10.1 & $1.63(1.10-2.41)$ & 0.015 \\
Responding group (n=129) & & & & \\
$\quad$ Preoperative chemotherapy cycles $\geq 8$ & 6.4 & 14.8 & $3.37(1.56-7.32)$ & 0.002 \\
$\quad$ Bilobar distribution & 7.4 & 15.2 & $1.84(1.18-2.88)$ & 0.007 \\
Non-responding group (n=99) & & & & \\
$\quad$ Intraoperative RFA & 5.1 & 4.4 & $1.70(1.00-2.86)$ & 0.048 \\
$\quad \geq 4$ hepatic metastases & 4.2 & 0 & $1.87(1.35-2.58)$ & 0.000 \\
\hline
\end{tabular}

RFA=Radiofrequency Ablation. $C R L M=$ Colorectal Liver Metastases. RFS=Recurrence Free Survival. HR=Hazard Ratio. $\mathrm{CI}=$ Confidence Interval.

hepatectomy alone. The results justified the adjunct use of RFA in hepatectomy for selected patients. Whereas, detailed indications and contraindications for this treatment is still unclear.

RFA is usually regarded as an alternative therapeutic option with poor disease control for unresectable CRLM [2324]. Indeed, local recurrence rate following hepatectomy-RFA was significantly higher in the entire study population $(31.9 \%$ vs. $18.2 \%, p=0.023)$ and non-responding group $(48.1 \%$ vs. $23.6 \%, \mathrm{p}=0.018)$. Nevertheless, this was not observed in chemotherapy-responsive patients $(21.4 \%$ vs. $13.8 \%$, $\mathrm{p}=0.271$ ). Although patients who underwent hepatectomyRFA were characterized by a larger tumor burden, the responding group showed similar long-term survival after 
Table 4: Patterns of recurrence sorted by treatment

\begin{tabular}{|c|c|c|c|}
\hline & Hepatectomy+RFA n=69 $(\%)$ & Hepatectomy $n=159(\%)$ & $\mathbf{P}$ \\
\hline Overall recurrence & $53(76.8)$ & $114(71.7)$ & 0.423 \\
\hline Intrahepatic recurrence & $44(63.8)$ & $84(52.8)$ & 0.126 \\
\hline Ablation site & $12(17.4)$ & - & \\
\hline Resection margin & $10(14.5)$ & $29(18.2)$ & 0.49 \\
\hline Local recurrence & $22(31.9)$ & $29(18.2)$ & 0.023 \\
\hline New metastases & $22(31.9)$ & $55(34.6)$ & 0.691 \\
\hline Intra + Extrahepatic recurrence & $5(7.2)$ & $23(14.5)$ & 0.127 \\
\hline Extrahepatic recurrence & $4(5.8)$ & $7(4.4)$ & 0.738 \\
\hline
\end{tabular}

$\mathrm{RFA}=$ Radiofrequency Ablation. Local recurrence $=$ ablation site and resection margin recurrence

two treatment modalities. Besides, rate of recurrence at the ablation site was comparable to that at the margin after resection alone, which is similar to the result of a study from Eltawil et al [25]. The authors reviewed 24 patients who underwent hepatectomy-RFA for CRLM and demonstrated an ablation site local recurrence rate of $9.5 \%$, which compared favorably among patients who underwent hepatectomy alone (20\%), suggesting that RFA is not associated with an excess ablation site recurrence. Prospective survival data for patients treated with chemotherapy-RFA also comfirmed our results. The CLOCC trial (chemotherapy alone versus chemotherapy + RFA) reported a 3-year PFS of 27.6\% and OS at 30 months of $61.7 \%$ in the RFA arm [16]. ARF 2003 (chemotherapy + RFA + surgery) found a 3-year PFS of $10 \%$ and 30 months OS of $74 \%$ [17]. These results were comparable to those of patients who underwent hepatectomy-RFA in the responding group (3-year RFS: 24.4\%, 30 months OS:68.2\%). Therefore, hepatectomy-RFA should be used for those needed if there is radiological response to prior systemic therapy.

Several studies have demonstrated that progression while preoperative chemotherapy is not an absolute contraindication to liver resection for patients whose disease remains resectable [26-27]. The major concern is the treatment of patients with CRLM whose disease remains unresectable after preoperative chemotherapy.
Is liver resection in combination with intraoperative RFA indicated, or should further chemotherapy regimens be planned? Given the low objective response rates to second-line chemotherapy [28-30] and the lack of other effective treatment options for patients with no response to chemotherapy, rescue surgery consist of hepatectomy and RFA was sometimes introduced as an alternative therapeutic option in our hospital. However, whether this treatment modality could work as effectively as hepatectomy alone in non-responsive patients is largely unknown. To our knowledge, few studies have focused on this topic. Our results suggested that hepatectomyRFA provided significantly worse outcome with 3-year OS rate of $12 \%$, and 3 -year RFS rate of $4.4 \%$ in patients with downstaging not achieved. This long term result even seems inferior to that of palliative chemotherapy [31-32], which seem to be a result of high major complications rate $(29 \%)$ and overall recurrence rate $(92.6 \%)$ following hepatectomy-RFA. Even though one might argue the outcome may be a result of a selection bias, intraoperative RFA showed an independent association with decreased OS and RFS after adjusting for other clinical and pathological factors.

Patients undergoing hepatectomy-RFA mostly had worse tumor biology than those undergoing hepatectomy
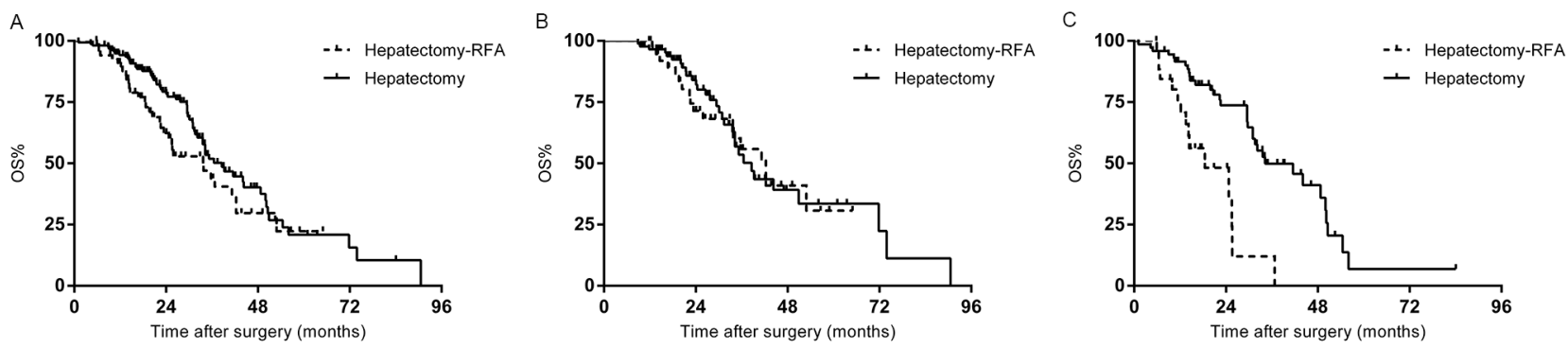

Figure 1: (A) Overall survival (OS) of the whole study population stratified by hepatectomy with or without RFA. (B) OS of the responding group stratified by hepatectomy with or without RFA. (C) OS of the non-responding group stratified by hepatectomy with or without RFA. 
Table 5: Patterns of recurrence according to the response to preoperative chemotherapy

\begin{tabular}{|c|c|c|c|c|c|c|}
\hline & \multicolumn{2}{|c|}{ Responding group } & \multicolumn{4}{|c|}{ Non-responding group } \\
\hline & $\begin{array}{c}\text { Hepatectomy+RFA } \\
n=42(\%)\end{array}$ & $\begin{array}{c}\text { Hepatectomy } n=87 \\
(\%)\end{array}$ & $\mathbf{p}$ & $\begin{array}{c}\text { Hepatectomy+RFA } \\
\mathbf{n}=\mathbf{2 7}(\%)\end{array}$ & $\begin{array}{c}\text { Hepatectomy } n=72 \\
(\%)\end{array}$ & $\mathbf{p}$ \\
\hline Overall recurrence & $28(66.7)$ & $59(67.8)$ & 0.896 & $25(92.6)$ & $55(76.4)$ & 0.068 \\
\hline $\begin{array}{l}\text { Intrahepatic } \\
\text { recurrence }\end{array}$ & $23(54.8)$ & $44(50.6)$ & 0.656 & $21(77.8)$ & $40(55.6)$ & 0.043 \\
\hline Ablation site & $5(11.9)$ & - & - & $7(25.9)$ & - & - \\
\hline Resection margin & $4(9.5)$ & $12(13.8)$ & 0.491 & $6(22.2)$ & $17(23.6)$ & 1.0 \\
\hline Local recurrence & $9(21.4)$ & $12(13.8)$ & 0.271 & $13(48.1)$ & $17(23.6)$ & 0.018 \\
\hline New metastases & $14(33.3)$ & $32(36.8)$ & 0.515 & $8(29.6)$ & 23(31.9) & 0.825 \\
\hline $\begin{array}{l}\text { Intra+Extrahepatic } \\
\text { recurrence }\end{array}$ & $3(7.1)$ & $11(12.6)$ & 0.523 & $2(7.4)$ & $12(16.7)$ & 0.339 \\
\hline $\begin{array}{l}\text { Extrahepatic } \\
\text { recurrence }\end{array}$ & $2(4.8)$ & $4(4.6)$ & 1.0 & $2(7.4)$ & $3(4.2)$ & 0.612 \\
\hline
\end{tabular}

RFA $=$ Radiofrequency Ablation. Local recurrence $=$ ablation site and resection margin recurrence

alone. For responding group, hepatectomy-RFA can make patients with high tumor burden achieve a long-term outcome comparable to that of patients with favorable tumor biology. However, hepatectomy-RFA does not add any value for chemo-resistant patients, which may be attributed to the limited potential for postoperative systemic chemotherapy to cure residual micro-metastases left behind after surgery in this cohort of patients. Indeed, prolonged preoperative chemotherapy required for downstaging was associated with decreased RFS and OS
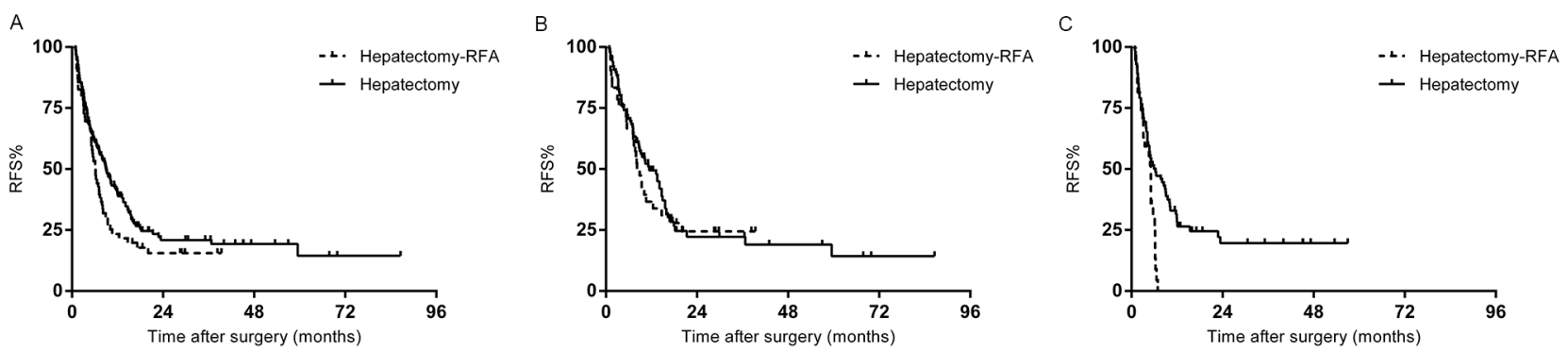

Figure 2: (A) Recurrence free survival (RFS) of the whole study population stratified by hepatectomy with or without RFA. (B) RFS of the responding group stratified by hepatectomy with or without RFA. (C). RFS of the non-responding group stratified by hepatectomy with or without RFA.
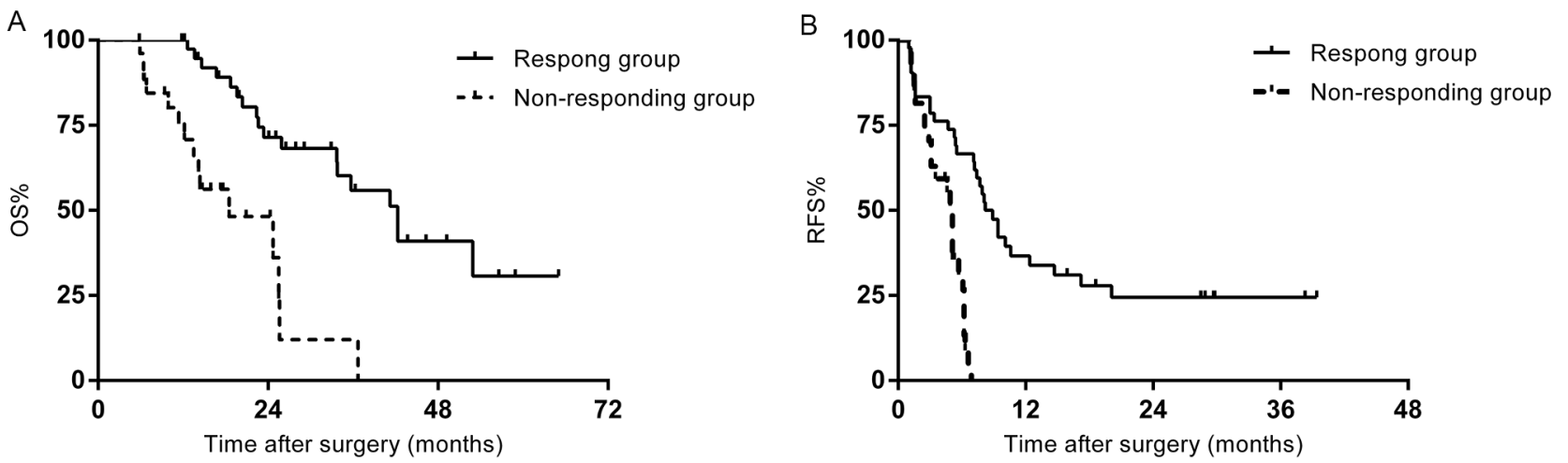

Figure 3: (A) OS of the patients who underwent hepatectomy-RFA stratified by chemotherapy response. (B) RFS of the patients who underwent hepatectomy-RFA stratified by chemotherapy response. 
in the responding group, suggesting significant effects of the extent of chemo-sensitivity on reducing recurrence and prolonging survival. Sasaki et al [33] recently performed a retrospective study of 485 patients who underwent curative hepatectomy and identified primary tumor nodal metastases, KRAS mutation, and preoperative high CEA related to survival. For patients who underwent hepatectomy-RFA, those with no or one risk factor had a 5-year OS rate similar to patients treated with resection alone. In contrast, patients with two or more risk factors had a much worse prognosis. The findings imply that patients who would benefit the most from hepatectomyRFA could be selected using tumor biology related factors, among which chemotherapy response may play an important role.

This study had some limitations. First, it was a retrospective study with relatively small sample size. Second, operations were performed by different surgeons, with their own criteria regarding patients selection for resection or hepatectomy-RFA. What's more, some lesions judged to be unresectable in the past may now be treated by resection alone, with improved surgical techniques and skills, which may result in selection bias. Furthermore, only patients with no extrahepatic disease were eligible for the current study and these represent only a proportion of patients with CRLM. Last but not least, preoperative chemotherapy regimen was not standardized and this is also a major source of bias.

\section{MATERIALS AND METHODS}

\section{Inclusion criteria}

Patients who underwent surgery for CRLM at the Department of hepatobiliary surgery, Cancer Hospital, Chinese Academy of Medical Sciences between January 1, 2004, and December 31, 2015, were identified from our prospective institutional database. In these patients, patients who met the following criteria were considered for further analysis. Inclusion criteria were: (1) histologically proven colorectal adenocarcinoma liver metastases; (2) preoperative chemotherapy was given, followed by hepatectomy with or without intraoperative RFA for curative intents. Excluion criteria were: (1) extrahepatic metastases detected on preoperative imaging or during surgery; (2) R2 resection; (3) postoperative deaths (noncancer-related 90-day mortality); or (4) a history of prior hepatectomy for CRLM. In total, 228 patients met the eligibility criteria.

\section{Perioperative management}

All patients were evaluated preoperatively, including carcinoembryonic antigen (CEA) levels; abdominopelvic computed tomography (CT) and magnetic resonance imaging (MRI); and chest radiography or chest CT to determine the disease stage. Preoperative chemotherapy was mainly recommended to patients with initially un m table liver metastases; or to patients with multiple high-risk factors: synchronous metastases, $\geq 4$ hepatic lesions, primary tumor invading nearby tissues/organs and imaged mesenteric nodal disease. The definitions of unresectability were as follows: multiple liver metastases that required resection of more than $70 \%$ of non-tumor liver for removal of all tumors, tumors invading all three hepatic veins, tumors invading both the left and right branches of the hepatic artery or portal vein, and unresectable extrahepatic metastases. Chemotherapy was composed of a combination of 5-fluorouracil/capecitabine and oxaliplatin/irinotecan with or without bevacizumab and cetuximab. Tumor response was assessed according to the Response Evaluation Criteria In Solid Tumors criteria (RECIST, version 1.1) every two cycles. Complete response (CR) was defined as the disappearance of all signs of the current disease recorded from the start of the treatment. Partial response $(\mathrm{PR})$ was defined as a decrease in the size of the tumor of $\sim 30 \%$. Stable disease (SD) was defined as no disease progression or regression. Progressive disease (PD) was defined as an increase in the tumor size of $>20 \%$ during or after treatment. All imaging studies were reviewed by at least two independent radiologists until the final conclusion was drawn. Surgery with curative intent was performed for hepatic lesions considered to be treatable by hepatecomy \pm RFA, with the residue liver volume of at least $30 \%$. The decision to undertake surgery for controversial cases was reached by consensus of a multidisciplinary team (MDT) including surgeons, oncologists and radiologists.

During surgery, the peritoneal cavity was inspected to exclude previously undetected extrahepatic lesions. Manual liver palpation and intra-operative ultrasound were used to rule out occult lesions and confirm the number, size and location of the liver metastases. If all the lesions were deemed resectable, hepatectomies alone were undertaken. Neither the number nor the size of metastases excluded any patients from resection. Patients were treated with intraoperative RFA when one hepatic lesion was considered unresectable because of deep location or proximity to major vascular structures, so as to avoid extensive hepatectomy, especially for lesions less than $3 \mathrm{~cm}$. The principle of surgery was to remove all detectable lesions with a tumorfree margin. After resection of the resectable metastases, intraoperative ultrasound was performed to guide placement of the RFA needle into the remaining lesions and then ablation was started. Successful ablation was defined as the complete destruction of the tumor with at least a $1-\mathrm{cm}$ zone of normal liver parenchyma in real-time ultrasound. All specimens were subjected to histological evaluation to confirm the pathological diagnosis, number and size of liver lesions, and the width of the surgical margin. In case of multiple liver metastases, the diameter of the largest lesion was defined as the final size, and the closest margin was 
recorded. R1 resection was defined with a distance from the metastasis edge to the transection line of less than $1 \mathrm{~mm}$.

Postoperative complications were graded according to the Clavien system, and major complications were defined as any grade III or IV complication. After discharge, adjuvant chemotherapy was recommended to most patients.

\section{Follow-up}

After surgery, patients were followed up at regular intervals. Serum CEA and imaging studies were performed to detect any intrahepatic recurrence or distant metastases. The first follow-up occurred one month post-surgery, with subsequent ones every 3 months for up to 2 years, and every 6 months thereafter.

\section{Statistical analysis}

Continuous variables are expressed as the median (range). Continuous and categorical variables were compared by Mann-Whitney U test and Chi square test or Fisher's exact test respectively. Survival analyses were carried out using the Kaplan-Meier method, with group comparisons by the log rank test. Multivariate models were used for OS and RFS using the Cox proportional hazard method. Clinicopathological factors were included in each model if they achieved a $p<0.1$ for significance in univariate regression analysis. Use of RFA was included in each model, irrespective of statistical significance. $\mathrm{P}<0.05$ was considered to indicate statistical significance. OS was estimated from liver resection to death; RFS was from liver resection to the first documented disease recurrence. Statistical analyses were performed using the SPSS, version 22, Armonk NV, USA.

\section{CONCLUSIONS}

This study showed that hepatectomy-RFA in patients who respond to preoperative chemotherapy is feasible and may be associated with a long-term outcome similar to that after hepatectomy alone. However, the poor results obtained by hepatectomy-RFA in patients with tumor stablization/progression suggest that non-response to preoperative chemotherapy is a contraindication to this treatment in patients with CRLM, and further chemotherapy may be a more reasonable choice for these patients. Chemotherapy response could be a useful tool for selecting patients for hepatectomy-RFA.

\section{ACKNOWLEDGMENTS AND FUNDING}

This study was supported by National Natural Science Foundation of China (81672461,81350007), the National High-tech R\&D (863) Program of China (2015AA020408), the capital health research and development of special (2014-1-4022), and CAMS Innovation Fund for Medical Sciences (CIFMS) (Grant no.2016-I2M-1-001).

\section{CONFLICTS OF INTEREST}

The authors declare that they have no conflicts of interest.

\section{REFERENCES}

1. Van Cutsem E, Nordlinger B, Adam R, Köhne CH, Pozzo C, Poston G, Ychou M, Rougier P, and European Colorectal Metastases Treatment Group. Towards a pan-European consensus on the treatment of patients with colorectal liver metastases. Eur J Cancer. 2006; 42:2212-21.

2. Yoo PS, Lopez-Soler RI, Longo WE, Cha CH. Liver resection for metastatic colorectal cancer in the age of neoadjuvant chemotherapy and bevacizumab. Clin Colorectal Cancer. 2006; 6:202-07.

3. Kopetz S, Chang GJ, Overman MJ, Eng C, Sargent DJ, Larson DW, Grothey A, Vauthey JN, Nagorney DM, McWilliams RR. Improved survival in metastatic colorectal cancer is associated with adoption of hepatic resection and improved chemotherapy. J Clin Oncol. 2009; 27:3677-83.

4. Cucchetti A, Ferrero A, Cescon M, Donadon M, Russolillo N, Ercolani G, Stacchini G, Mazzotti F, Torzilli G, Pinna AD. Cure model survival analysis after hepatic resection for colorectal liver metastases. Ann Surg Oncol. 2015; 22:1908-14.

5. Nordlinger B, Sorbye H, Glimelius B, Poston GJ, Schlag PM, Rougier P, Bechstein WO, Primrose JN, Walpole ET, Finch-Jones M, Jaeck D, Mirza D, Parks RW, et al, and EORTC Gastro-Intestinal Tract Cancer Group, and Cancer Research UK, and Arbeitsgruppe Lebermetastasen und-tumoren in der Chirurgischen Arbeitsgemeinschaft Onkologie (ALM-CAO), and Australasian Gastro-Intestinal Trials Group (AGITG), and Fédération Francophone de Cancérologie Digestive (FFCD). Perioperative chemotherapy with FOLFOX4 and surgery versus surgery alone for resectable liver metastases from colorectal cancer (EORTC Intergroup trial 40983): a randomised controlled trial. Lancet. 2008; 371:1007-16.

6. Alberts SR, Horvath WL, Sternfeld WC, Goldberg RM, Mahoney MR, Dakhil SR, Levitt R, Rowland K, Nair S, Sargent DJ, Donohue JH. Oxaliplatin, fluorouracil, and leucovorin for patients with unresectable liver-only metastases from colorectal cancer: a North Central Cancer Treatment Group phase II study. J Clin Oncol. 2005; 23:9243-49.

7. Ychou M, Viret F, Kramar A, Desseigne F, Mitry E, Guimbaud R, Delpero JR, Rivoire M, Quénet F, Portier G, Nordlinger B. Tritherapy with fluorouracil/leucovorin, irinotecan and oxaliplatin (FOLFIRINOX): a phase II study in colorectal cancer patients with non-resectable liver metastases. Cancer Chemother Pharmacol. 2008; 62:195-201.

8. Barone C, Nuzzo G, Cassano A, Basso M, Schinzari G, Giuliante F, D'Argento E, Trigila N, Astone A, Pozzo C. Final analysis of colorectal cancer patients treated with irinotecan and 5-fluorouracil plus folinic acid neoadjuvant 
chemotherapy for unresectable liver metastases. Br J Cancer. 2007; 97:1035-39.

9. Ho WM, Ma B, Mok T, Yeo W, Lai P, Lim R, Koh J, Wong YY, King A, Leow CK, Chan AT. Liver resection after irinotecan, 5-fluorouracil, and folinic acid for patients with unresectable colorectal liver metastases: a multicenter phase II study by the Cancer Therapeutic Research Group. Med Oncol. 2005; 22:303-12.

10. Folprecht G, Grothey A, Alberts S, Raab HR, Köhne CH. Neoadjuvant treatment of unresectable colorectal liver metastases: correlation between tumour response and resection rates. Ann Oncol. 2005; 16:1311-19.

11. Andres A, Toso C, Adam R, Barroso E, Hubert C, Capussotti L, Gerstel E, Roth A, Majno PE, Mentha G. A survival analysis of the liver-first reversed management of advanced simultaneous colorectal liver metastases: a LiverMetSurvey-based study. Ann Surg. 2012; 256:772-78.

12. Abdalla EK, Vauthey JN, Ellis LM, Ellis V, Pollock R, Broglio KR, Hess K, Curley SA. Recurrence and outcomes following hepatic resection, radiofrequency ablation, and combined resection/ablation for colorectal liver metastases. Ann Surg. 2004; 239:818-825.

13. Gleisner AL, Choti MA, Assumpcao L, Nathan H, Schulick RD, Pawlik TM. Colorectal liver metastases: recurrence and survival following hepatic resection, radiofrequency ablation, and combined resectionradiofrequency ablation. Arch Surg. 2008; 143:1204-12.

14. van Amerongen MJ, van der Stok EP, Fütterer JJ, Jenniskens SF, Moelker A, Grünhagen DJ, Verhoef C, de Wilt JH. Short term and long term results of patients with colorectal liver metastases undergoing surgery with or without radiofrequency ablation. Eur J Surg Oncol. 2016; 42:523-30.

15. Tsai S, Pawlik TM. Outcomes of ablation versus resection for colorectal liver metastases: are we comparing apples with oranges? Ann Surg Oncol. 2009; 16:2422-28.

16. Ruers T, Punt C, Van Coevorden F, Pierie JP, BorelRinkes I, Ledermann JA, Poston G, Bechstein W, Lentz MA, Mauer M, Van Cutsem E, Lutz MP, Nordlinger B, and EORTC Gastro-Intestinal Tract Cancer Group, Arbeitsgruppe Lebermetastasen und-tumoren in der Chirurgischen Arbeitsgemeinschaft Onkologie (ALM$\mathrm{CAO}$ ) and the National Cancer Research Institute Colorectal Clinical Study Group (NCRI CCSG). Radiofrequency ablation combined with systemic treatment versus systemic treatment alone in patients with non-resectable colorectal liver metastases: a randomized EORTC Intergroup phase II study (EORTC 40004). Ann Oncol. 2012; 23:2619-26.

17. Evrard S, Rivoire M, Arnaud J, Lermite E, Bellera C, Fonck M, Becouarn Y, Lalet C, Puildo M, MathoulinPelissier S. Unresectable colorectal cancer liver metastases treated by intraoperative radiofrequency ablation with or without resection. Br J Surg. 2012; 99:558-65.

18. Nielsen K, Scheffer HJ, Volders JH, van der Vorst MJ, van Tilborg AA, Comans EF, de Lange-de Klerk ES, Sietses C, Meijer S, Meijerink MR, van den Tol MP. Radiofrequency Ablation to Improve Survival After Conversion Chemotherapy for Colorectal Liver Metastases. World J Surg. 2016; 40:1951-58.

19. Kawamura J, Yazawa T, Sumida K, Kida Y, Ogawa R, Tani M, Kawasoe J, Yamamoto M, Harada H, Yamamoto H, Zaima M. Clinical efficacy of liver resection after downsizing systemic chemotherapy for initially unresectable liver metastases. World J Surg Oncol. 2016; $14: 56$.

20. Lam VW, Spiro C, Laurence JM, Johnston E, Hollands MJ, Pleass HC, Richardson AJ. A systematic review of clinical response and survival outcomes of downsizing systemic chemotherapy and rescue liver surgery in patients with initially unresectable colorectal liver metastases. Ann Surg Oncol. 2012; 19:1292-301.

21. Kataoka K, Kanazawa A, Iwamoto S, Kato T, Nakajima A, Arimoto A. Does "conversion chemotherapy" really improve survival in metastatic colorectal cancer patients with liver-limited disease? World J Surg. 2014; 38:936-46.

22. Imai K, Allard MA, Castro Benitez C, Vibert E, Sa Cunha A, Cherqui D, Castaing D, Baba H, Adam R. Longterm outcomes of radiofrequency ablation combined with hepatectomy compared with hepatectomy alone for colorectal liver metastases. Br J Surg. 2017; 104:570-79.

23. Stoltz A, Gagnière J, Dupré A, Rivoire M. Radiofrequency ablation for colorectal liver metastases. J Visc Surg. 2014; 151:S33-44.

24. Bai H, Huangz X, Jing L, Zeng Q, Han L. The effect of radiofrequency ablation vs. liver resection on survival outcome of colorectal liver metastases (CRLM): a metaanalysis. Hepatogastroenterology. 2015; 62:373-77.

25. Eltawil KM, Boame N, Mimeault R, Shabana W, Balaa FK, Jonker DJ, Asmis TR, Martel G. Patterns of recurrence following selective intraoperative radiofrequency ablation as an adjunct to hepatic resection for colorectal liver metastases. J Surg Oncol. 2014; 110:734-38.

26. Neumann UP, Thelen A, Röcken C, Seehofer D, Bahra M, Riess H, Jonas S, Schmeding M, Pratschke J, Bova R, Neuhaus P. Nonresponse to pre-operative chemotherapy does not preclude long-term survival after liver resection in patients with colorectal liver metastases. Surgery. 2009; $146: 52-59$

27. Viganò L, Capussotti L, Barroso E, Nuzzo G, Laurent C, Ijzermans JN, Gigot JF, Figueras J, Gruenberger T, Mirza DF, Elias D, Poston G, Letoublon C, et al. Progression while receiving preoperative chemotherapy should not be an absolute contraindication to liver resection for colorectal metastases. Ann Surg Oncol. 2012; 19:2786-96. 
28. Kim GP, Sargent DJ, Mahoney MR, Rowland KM Jr, Philip PA, Mitchell E, Mathews AP, Fitch TR, Goldberg RM, Alberts SR, Pitot HC. Phase III noninferiority trial comparing irinotecan with oxaliplatin, fluorouracil, and leucovorin in patients with advanced colorectal carcinoma previously treated with fluorouracil: N9841. J Clin Oncol. 2009; 27:2848-54.

29. Seymour MT, Maughan TS, Ledermann JA, Topham C, James R, Gwyther SJ, Smith DB, Shepherd S, Maraveyas A, Ferry DR, Meade AM, Thompson L, Griffiths GO, et al, and FOCUS Trial Investigators, and National Cancer Research Institute Colorectal Clinical Studies Group. Different strategies of sequential and combination chemotherapy for patients with poor prognosis advanced colorectal cancer (MRC FOCUS): a randomised controlled trial. Lancet. 2007; 370:143-52.

30. Brouquet A, Overman MJ, Kopetz S, Maru DM, Loyer EM, Andreou A, Cooper A, Curley SA, Garrett CR, Abdalla EK, Vauthey JN. Is resection of colorectal liver metastases after a second-line chemotherapy regimen justified? Cancer. 2011; 117:4484-92.

31. Van Cutsem E, Köhne CH, Hitre E, Zaluski J, Chang Chien CR, Makhson A, D'Haens G, Pintér T, Lim R, Bodoky G, Roh JK, Folprecht G, Ruff P, et al. Cetuximab and chemotherapy as initial treatment for metastatic colorectal cancer. N Engl J Med. 2009; 360:1408-17.

32. Adams RA, Meade AM, Seymour MT, Wilson RH, Madi A, Fisher D, Kenny SL, Kay E, Hodgkinson E, Pope M, Rogers P, Wasan H, Falk S, et al, and MRC COIN Trial Investigators. Intermittent versus continuous oxaliplatin and fluoropyrimidine combination chemotherapy for first-line treatment of advanced colorectal cancer: results of the randomised phase $3 \mathrm{MRC}$ COIN trial. Lancet Oncol. 2011; 12:642-53.

33. Sasaki K, Margonis GA, Andreatos N, Kim Y, Wilson A, Gani F, Amini N, Pawlik TM. Combined resection and RFA in colorectal liver metastases: stratification of long-term outcomes. J Surg Res. 2016; 206:182-89. 